\title{
Testing the impact of laboratory reared indigenous leafroller (Lepidoptera: Tortricidae) parasitoids (Hymenoptera: Ichneumonidae, Braconidae) on sentinel hosts in controlled orchard releases
}

\author{
JOAN E. COSSENTINE \\ Agriculture and Agri-Food Canada, 4200 Highway 97, Box 5000, Pacific Agri-Food Research Centre, Summerland, BC, \\ V0H 1 Z0 Canada; e-mail: cossentinej@agr.gc.ca
}

\begin{abstract}
Key words. Braconidae, Apanteles polychrosidis, Macrocentrus linearis, Ichneumonidae, Apophua simplicipes, Glypta variegata, Tortricidae, Choristoneura rosaceana, orchard release, parasitoid
\end{abstract}

\begin{abstract}
Leafrollers can experience high levels of indigenous parasitism in organically managed apple orchards and the augmentative release of specific parasitoid species to suppress these secondary pests may be advantageous in orchards converting to nonchemical pest management. Caged and uncaged releases of two ichneumonid [Apophua simplicipes (Cresson) and Glypta variegata Dasch] and two braconid (Macrocentrus linearis Nees and Apanteles polychrosidis Viereck) koinobiont endoparasitoids of the obliquebanded leafroller, Choristoneura rosaceana (Lepidoptera: Tortricidae) on host-infested potted apple trees were conducted to assess the parasitoids' abilities to find and successfully parasitize sentinel hosts under orchard conditions. Seasonal timing of the trials varied for each parasitoid species, based on their relative performance under simulated summer/fall conditions in laboratory trials. After the release of five or fifty parasitoid females, the mean percent parasitism of leafroller larvae collected from infested trees ranged from 0 to $75 \%$ depending on the parasitoid species involved. Although caged releases tended to increase the percentage of live parasitized hosts in release treatments, uncaged releases provided a more realistic assessment of the parasitoid's ability to seek and find hosts within an infested area over a longer period. Release of the large, solitary A. simplicipes, had the most significant impact on the host population density.
\end{abstract}

\section{INTRODUCTION}

Apple orchards in the interior of British Columbia, Canada are part of an area-wide sterile male codling moth, Cydia pomonella (L.) (Lepidoptera: Tortricidae) release program (Dyck \& Gardiner, 1992). Where this biological control strategy has been successful, there has been a substantial reduction in the use of codling mothtargeted chemical insecticides that also suppressed other susceptible secondary orchard insects such as leafrollers (Lepidoptera: Tortricidae). High levels of obliquebanded leafroller, Choristoneura rosaceana (Harris) (Lepidoptera: Tortricidae) parasitism have been recorded in certified organically managed orchards within this program (Cossentine et al., 2004a) and the orchardists frequently rely on high parasitism to suppress leafroller populations. It would be advantageous to augment the incidence of efficacious leafroller parasitoid species in formerly chemically managed orchards which no longer require multiple codling moth targeted chemical sprays and do not host leafroller parasitoids, however studies are required to assess the ability of specific parasitoid species to effectively find and parasitize hosts in orchard releases.

Apophua simplicipes (Cresson), Glypta variegata Dasch (Hymenoptera: Ichneumonidae), Macrocentrus linearis Nees and Apanteles polychrosidis Viereck (Hymenoptera: Braconidae) are common indigenous, koinobiont endoparasitoids of early-instar obliquebanded leafroller larvae in organically managed orchards in the southern region of the above codling moth area-wide con- trol program (Cossentine et al., 2004a). All four parasitoid species emerge from leafroller larvae in the spring, after the potentially bivoltine early instar host has overwintered and emerged to feed and mature on apple blossoms, foliage and developing apples (Chapman et al., 1968; Cossentine et al., 2004a). Adult obliquebanded leafrollers from overwintering larvae produce a summer generation and a second generation occurs in late summer and early fall (Madsen \& Procter, 1982). All of the above parasitoids, except possibly the G. variegata, are also bivoltine as they have been recorded to emerge from the summer leafroller generation (Cossentine et al., 2004a).

The biology of each of the four parasitoids has been studied under laboratory conditions (Cossentine et al., 2004b, 2005, 2007), but laboratory derived data may not accurately reflect the parasitoids' potential performance when released into real agro-ecosystems (Van Lenteren \& Woets, 1988). A recommended step in the evaluation of parasitoid species for augmentative release is to test the ability of each candidate to find the host on the correct crop under realistic conditions (Van Driesche \& Bellows, 1996). Obliquebanded leafrollers are not easily communally reared, making mass-rearing of the parasitoids expensive and wild host larval population densities are unreliable. Both these factors limit the success of orchard release trials. In this study, a more controlled field release was designed that required reasonably low numbers of parasitoids and ensured a sufficient number of available hosts. Laboratory-reared female parasitoids were released at two rates on caged and uncaged obliquebanded 
leafroller infested potted trees in order to assess the ability of each laboratory species to find and parasitize the host under realistic semi-orchard conditions. Although the response of parasitoids to host density is important in determining their efficacy (Bezemer \& Mills, 2001) it was not evaluated in these trials as it is difficult to accurately determine the number of early instar leafroller that are established per tree without causing larval movement and mortality.

\section{MATERIAL AND METHODS}

\section{Infested potted trees}

Fifty-four (and one week later, an additional 27) two to four year-old potted Royal Gala apple trees, similar in size to trees found in newly established high-density orchard plantings, were infested with laboratory colony derived neonate obliquebanded leafrollers before each trial to allow them to develop to second instars. Each tree either had a leafroller egg mass (75 to 150 eggs per mass, Madsen \& Procter, 1982) stapled to a leaf from which neonates emerged within one or two days, or neonates were manually placed on the tree with a brush. Successful establishment was similar for both life stages. The trees were infested outdoors inside a $2.4 \times 3.7 \times 2.4 \mathrm{~m}$ screen cage to avoid exposure to parasitoids and predators. Obliquebanded leafroller density between trees was assumed to be relatively uniform due to the close proximity of the trees (touching) while infested and the active dispersive nature of the neonates (Carrière, 1992). Three $2.4 \times 3.7 \times 2.4 \mathrm{~m}$ screen cages with zippered doors, supported by metal frames, were placed adjacent to a pesticide-free apple orchard. Nine randomly chosen leafroller-infested potted apple trees were placed inside each cage in an X pattern. Three groups of nine randomly chosen trees were placed uncaged in a similar pattern within the orchard; each group was widely separated over an one ha area. Four 59.2-ml plastic cups, containing cotton wicks soaked with $10 \%$ honey water and supported by 1 $\mathrm{m}$ sticks, were placed as parasitoid feeding stations within each treatment. The honey water was replenished as required.

\section{Parasitoids}

All female parasitoids used in the releases were from laboratory colonies reared on obliquebanded leafrollers on an agarbased pinto-bean diet (modified from Shorey \& Hale, 1965). They were all $\leq$ five day old adults, allowed to mate and one day prior to release, all were exposed to early instar leafrollers feeding on apple leaves. During this pre-release exposure the female parasitoids actively antennated and probed the infested leaves. This pre-release conditioning was included to maximize the recognition of hosts under field conditions, as parasitoids reared on artificial diets do not come into contact with all wild host chemical clues (Noldus, 1989; Lewis \& Martin, 1990).

On the first day of the trials, 0 (control), 5 (low release) or 50 (high release) parasitoid females (and an equivalent number of males) were released on the centre caged and uncaged trees. One week later, all leaves on the potted trees within each treatment were inspected and those with evidence of leafrollers were removed. The trees were replaced with new second instarinfested potted trees in the uncaged half of the study only. There was potential for surviving parasitoids to enter and exit cages while trees were exchanged, therefore infested potted trees were not placed inside cages for a second week. Movement between treatments, natural parasitism and predation would be expected to occur in the uncaged treatments. Additional parasitoids were not released and seven days later, all leaves with evidence of leafrollers were removed.

\section{Data collection}

All removed leaves were examined under a dissecting microscope to find associated leafroller larvae. The large dark eggs of A. simplicipes and $G$. variegata are visible through the host integument, therefore for these assessments, collected leafrollers were classified as parasitized (one or more egg visible), unparasitized (no egg visible), dead or dead and parasitized. In the two braconid trials, collected leafrollers were classified as dead or alive. All living larvae (parasitized or not) were placed on the meridic diet mentioned above, in separate $30 \mathrm{ml}$ plastic cups and held at $25^{\circ} \mathrm{C}$ until host or parasitoid pupation. Parasitoid emergence constituted successful parasitism.

\section{Timing of trials}

The trial was replicated twice over time for each parasitoid species over a three-year period with no temporal overlap among the trials. Test dates for each species were based on laboratory assessments and when early instar wild obliquebanded leafrollers would be encountered in orchards. In previous laboratory trials, A. simplicipes fecundity was not significantly different when the females were held at a constant 25 versus $15^{\circ} \mathrm{C}$ (Cossentine et al., 2004b). Apophua simplicipes field trials were carried out September 6 to October 11, 2002 (average maximum and minimum temperatures: $20.2 \pm 4.7^{\circ} \mathrm{C}$ and $5.3 \pm 3.1^{\circ} \mathrm{C}$ ) to coincide with the natural presence of wild second instar larvae in the orchards. To date, G. variegata have only been found emerging from overwintering hosts in the region of the trials, therefore the field test was conducted June 13 to July 14, 2003 (average maximum and minimum temperatures: $27.1 \pm 4.4^{\circ} \mathrm{C}$ and $12.8 \pm 3.2^{\circ} \mathrm{C}$ ), when wild adult $G$. variegata would be expected to be seeking hosts. In previous laboratory trials, parasitism of obliquebanded leafrollers by M. linearis was not significantly different when the females were held under summer conditions (fluctuating daily between 30.3 to $12.0^{\circ} \mathrm{C}$ ) versus fall conditions (Cossentine et al., 2005); M. linearis field trials were carried out August 1 to September 3, 2003 (average maximum and minimum temperatures: $30.3 \pm 2.9^{\circ} \mathrm{C}$ and $14.9 \pm 2.0^{\circ} \mathrm{C}$ ) when wild summer generation larvae would potentially be present in the orchard. In previous laboratory trials, A. polychrosidis fecundity was significantly higher when the females were held under fall conditions (fluctuating daily between 17.5 to $4.0^{\circ} \mathrm{C}$ ) versus summer conditions (Cossentine et al., 2005), therefore $A$. polychrosidis field trials were carried out September 13 to October 4, 2004 (average maximum and minimum temperatures: $18.1 \pm 3.0^{\circ} \mathrm{C}$ and $7.8 \pm 2.3^{\circ} \mathrm{C}$ ).

\section{Data analysis}

The effects of replication, cage and the parasitoid release treatments on total hosts recovered, percent dead host larvae and percent parasitism by the released species as well as wild species were determined with a split-plot analysis of variance (ANOVA) (SAS, 2000) for each week of the study, with the effect of trees nested in treatments. Data were also analyzed separately for caged or uncaged status. Percentages were arcsine-transformed before analysis. The difference between individual treatment means were determined using Tukey's Studentized range test (SAS, 2000) (Tables 1-3).

\section{RESULTS}

\section{Total sentinel host larvae recovered}

In the first week of the trials, neither replication nor the presence or absence of the cages had significant $(\mathrm{P}<$ 0.05 ) impact on the total number of obliquebanded leafroller larvae collected in the parasitoid trials. The parasitoid release treatments however did have significant 
TABLE 1. Mean number of obliquebanded leafroller larvae (OBLR) $( \pm \mathrm{SE})$ found on infested caged or uncaged potted apple trees one and two weeks post-release of 0 (control), 5 (low release) or 50 (high release) A. simplicipes, G. variegata, M. linearis or A. polychrosidis females. ( $\mathrm{N}=9$ trees, replicated twice over time.)

\begin{tabular}{|c|c|c|c|}
\hline \multirow[t]{2}{*}{ Treatment } & \multicolumn{3}{|c|}{$\begin{array}{l}\text { Mean number of OBLR found per tree per } \\
\text { release treatment (number of parasitoid females) }\end{array}$} \\
\hline & Control $(0)$ & Low release $(5)$ & High release $(50)$ \\
\hline \multicolumn{4}{|c|}{ A. simplicipes } \\
\hline Caged treatments - week 1 & $36.3 \pm 4.1 \mathrm{a}$ & $20.8 \pm 3.8 \mathrm{~b}$ & $5.2 \pm 0.9 \mathrm{c}$ \\
\hline Uncaged treatments - week 1 & $23.9 \pm 2.7 \mathrm{a}$ & $12.3 \pm 2.5 \mathrm{~b}$ & $8.3 \pm 1.4 b$ \\
\hline - week 2 & $13.2 \pm 3.6 \mathrm{a}$ & $16.0 \pm 4.0 \mathrm{a}$ & $17.8 \pm 4.6 \mathrm{a}$ \\
\hline \multicolumn{4}{|c|}{ G. variegata } \\
\hline Caged treatments - week 1 & $10.2 \pm 1.4 \mathrm{a}$ & $7.4 \pm 0.9 \mathrm{ab}$ & $4.0 \pm 0.8 \mathrm{~b}$ \\
\hline Uncaged treatments - week 1 & $5.9 \pm 1.1 \mathrm{a}$ & $5.9 \pm 0.8 \mathrm{a}$ & $4.1 \pm 0.8 \mathrm{a}$ \\
\hline - week 2 & $6.5 \pm 1.2 \mathrm{a}$ & $5.9 \pm 0.8 \mathrm{a}$ & $5.6 \pm 1.4 \mathrm{a}$ \\
\hline \multicolumn{4}{|c|}{ M. linearis } \\
\hline Caged treatments - week 1 & $12.8 \pm 2.9 \mathrm{a}$ & $8.6 \pm 2.2 \mathrm{a}$ & $7.5 \pm 1.9 \mathrm{a}$ \\
\hline Uncaged treatments - week 1 & $5.9 \pm 0.8 \mathrm{a}$ & $9.1 \pm 1.6 \mathrm{a}$ & $6.3 \pm 1.0 \mathrm{a}$ \\
\hline - week 2 & $6.7 \pm 1.8 \mathrm{a}$ & $10.9 \pm 2.7 \mathrm{a}$ & $6.0 \pm 0.9 \mathrm{a}$ \\
\hline \multicolumn{4}{|c|}{ A. polychrosidis } \\
\hline Caged treatments - week 1 & $14.1 \pm 1.6 \mathrm{a}$ & $16.5 \pm 3.3 \mathrm{a}$ & $12.6 \pm 2.1 \mathrm{a}$ \\
\hline Uncaged treatments - week 1 & $12.1 \pm 2.8 \mathrm{a}$ & $16.0 \pm 2.8 \mathrm{a}$ & $10.4 \pm 2.4 \mathrm{a}$ \\
\hline - week 2 & $13.2 \pm 2.7 \mathrm{a}$ & $8.9 \pm 1.6 \mathrm{a}$ & $13.0 \pm 1.7 \mathrm{a}$ \\
\hline
\end{tabular}

${ }^{1}$ Means within rows followed by the same lowercase letter are not significantly $(\mathrm{P}>0.05)$ different as determined by Tukey's Studentized range test (SAS, 2000).

effects on the total number of host larvae collected in the two ichneumonid trials: A. simplicipes $\left(\mathrm{F}_{2,78}=31.3, \mathrm{P}<\right.$ $0.0001)$ and $G$. variegata $\left(\mathrm{F}_{2,78}=9.2, \mathrm{P}=0.0003\right)$. In both cases, generally fewer larvae were collected in the release treatments than in the controls in the first week (Table 1). The number of larvae establishing on the potted trees in the first week of the $A$. simplicipes trials was higher than for all other trials and it is possible that these high artificial infestations may have influenced the significant reduction in the number of leafroller larvae collected, however, the $G$. variegata trials had host levels that were more consistent across trials. The parasitoid release treatments had no significant $(\mathrm{P}>0.05)$ effect on the total number of obliquebanded leafroller larvae collected in either of the two braconid release trials.

\section{Caged trials}

When only the data from the caged trials were analyzed, in week one, significantly fewer leafroller larvae were found on the trees exposed to the high A. simplicipes $\left(\mathrm{F}_{2,26}=20.5, \mathrm{P}<0.0001\right)$ and $G$. variegata release treatment $\left(\mathrm{F}_{2,26}=9.3, \mathrm{P}=0.0009\right)$ compared to the number found in control cages (Table 1).

\section{Uncaged trials}

Significantly fewer leafroller larvae were collected from the low and high $A$. simplicipes release trees in week one in the uncaged trees $\left(\mathrm{F}_{2,26}=10.5, \mathrm{P}=0.0005\right)$ than from control trees. The release of the other parasitoid species had no significant effect on the total number of leafroller larvae collected in uncaged treatments.

\section{Parasitism}

In the first week of the trials, replication had no significant impact $(\mathrm{P}>0.05)$ on the level of parasitism in any of the parasitoid trials and the presence or absence of cages only had a significant impact on parasitism in the $G$. variegata $\left(\mathrm{F}_{1,1}=3,220 ; \mathrm{P}=0.01\right)$ trials with more parasitism occurring in the cages (Table 2, Fig. 1).

\section{Caged trials}

As dispersal, predation and interspecific competition were suppressed in the cage releases, each of the parasitoid releases would be expected to have a significant impact on the percent of host parasitism occurring in the cages; however, due to the extremely low parasitism in the $M$. linearis release trials significant parasitism was only recorded for the other three species (A. simplicipes: $\mathrm{F}_{2,26}=45.2, \mathrm{P}<0.0001 ; G$. variegata: $\mathrm{F}_{2,26}=18.8, \mathrm{P}<$ 0.0001; A. polychrosidis: $\mathrm{F}_{2,26}=9.6, \mathrm{P}=0.0008$ ) (Tables 2-3, Figs 1-2). The highest parasitism was recorded in the $A$. simplicipes caged trial, accounting for means of over $70 \%$ of the collected host larvae (Table 2, Fig. 1). Significantly $(\mathrm{P}<0.05)$ more parasitized leafroller larvae survived under the lower pressure of five female $A$. simplicipes released per cage $(\bar{x}=58 \%$ alive and parasitized larvae per tree) versus the higher female release rate $(\bar{x}=$ $29 \%$ alive and parasitized larvae per tree). Conversely, significantly more parasitized larvae died when 50 female A. simplicipes were released per cage $(\bar{x}=46 \%$ dead and parasitized) versus when only five females were released ( $\bar{x}=18 \%$ dead and parasitized). In a similar fashion, significantly more parasitized leafroller larvae survived under the lower pressure of five female $G$. variegata 
TABLE 2. Mean percent of obliquebanded leafroller (OBLR) ( \pm SE) collected that were alive and parasitized (parasitoid developed), dead and parasitized (egg visible), dead and parasitized by other species one and two weeks post-release of 0 (control), 5 (low release) or 50 (high release) A. simplicipes or G. variegata females onto caged and uncaged infested potted apple tree $(\mathrm{N}=9$ trees, 2 replications).

\begin{tabular}{|c|c|c|c|c|c|c|}
\hline \multirow{3}{*}{$\begin{array}{l}\text { Time collected and host } \\
\text { status post-release }\end{array}$} & \multicolumn{6}{|c|}{ Mean $\%$ of collected OBLR larvae per release treatment } \\
\hline & \multicolumn{3}{|c|}{ Caged treatment } & \multicolumn{3}{|c|}{ Uncaged treatments } \\
\hline & Control (0) & Low (5) & $\operatorname{High}(50)$ & Control (0) & Low (5) & High (50) \\
\hline \multicolumn{7}{|c|}{ A. simplicipes (September - October releases) } \\
\hline \multicolumn{7}{|l|}{ WEEK 1} \\
\hline Total parasitized & $0 \pm 0 \mathrm{a}^{1}$ & $75.6 \pm 3.0 \mathrm{~b}$ & $75.0 \pm 5.0 \mathrm{~b}$ & $32.7 \pm 8.0 \mathrm{a}$ & $65.3 \pm 7.5 b$ & $72.1 \pm 7.1 \mathrm{~b}$ \\
\hline Alive \& parasitized & $0 \pm 0 \mathrm{a}$ & $57.8 \pm 3.3 \mathrm{c}$ & $29.0 \pm 5.7 b$ & $11.2 \pm 3.1 \mathrm{a}$ & $22.8 \pm 6.2 \mathrm{a}$ & $18.8 \pm 5.7 \mathrm{a}$ \\
\hline Dead \& parasitized & $0 \pm 0 \mathrm{a}$ & $17.7 \pm 2.3 \mathrm{a}$ & $46.0 \pm 5.9 \mathrm{~b}$ & $21.5 \pm 5.4 \mathrm{a}$ & $42.6 \pm 8.6 \mathrm{~b}$ & $51.0 \pm 8.0 \mathrm{~b}$ \\
\hline Dead & $28.6 \pm 2.7 \mathrm{~b}$ & $10.2 \pm 1.8 \mathrm{a}$ & $11.7 \pm 4.3 \mathrm{a}$ & $19.3 \pm 2.7 \mathrm{a}$ & $10.9 \pm 3.0 \mathrm{a}$ & $9.4 \pm 3.9 \mathrm{a}$ \\
\hline Parasitized by other species & $0 \pm 0$ & $0 \pm 0$ & $0 \pm 0$ & $7.7 \pm 2.8$ & $4.7 \pm 3.1 \mathrm{a}$ & $0.6 \pm 0.6 \mathrm{a}$ \\
\hline \multicolumn{7}{|l|}{ WEEK 2} \\
\hline Total parasitized & $\mathrm{na}^{2}$ & na & na & $8.1 \pm 2.7 \mathrm{a}$ & $4.0 \pm 1.6 \mathrm{a}$ & $22.7 \pm 5.8 \mathrm{~b}$ \\
\hline Alive $\&$ parasitized & na & na & na & $5.1 \pm 2.0 \mathrm{a}$ & $2.6 \pm 1.4 \mathrm{a}$ & $16.8 \pm 4.4 \mathrm{~b}$ \\
\hline Dead \& parasitized & na & na & na & $2.9 \pm 1.1 \mathrm{a}$ & $1.4 \pm 0.8 \mathrm{a}$ & $5.8 \pm 1.8 \mathrm{a}$ \\
\hline Dead & na & na & na & $29.8 \pm 6.2 \mathrm{a}$ & $31.8 \pm 7.1 \mathrm{a}$ & $22.9 \pm 7.1 \mathrm{a}$ \\
\hline Parasitized by other species & na & na & na & $13.9 \pm 3.6 \mathrm{a}$ & $10.4 \pm 3.4 \mathrm{a}$ & $2.7 \pm 0.9 \mathrm{a}$ \\
\hline \multicolumn{7}{|c|}{ G. variegata (June - July releases) } \\
\hline \multicolumn{7}{|l|}{ WEEK 1} \\
\hline Total parasitized & $0 \pm 0 \mathrm{aA}$ & $74.7 \pm 9.5 \mathrm{bA}$ & $44.2 \pm 9.4 \mathrm{bA}$ & $8.4 \pm 3.4 \mathrm{aA}$ & $1.6 \pm 1.6 \mathrm{aB}$ & $7.3 \pm 3.2 \mathrm{aB}$ \\
\hline Alive \& parasitized & $0 \pm 0 \mathrm{aA}$ & $68.7 \pm 5.8 \mathrm{cA}$ & $24.4 \pm 7.6 \mathrm{bA}$ & $6.0 \pm 2.5 \mathrm{bA}$ & $0 \pm 0 \mathrm{aA}$ & $0 \pm 0 \mathrm{aA}$ \\
\hline Dead \& parasitized & $0 \pm 0 \mathrm{aA}$ & $6.1 \pm 2.4 \mathrm{abA}$ & $19.8 \pm 6.6 \mathrm{bA}$ & $2.5 \pm 1.3 \mathrm{aA}$ & $1.6 \pm 1.6 \mathrm{aA}$ & $7.3 \pm 3.2 \mathrm{aB}$ \\
\hline Dead & $17.2 \pm 3.8 \mathrm{aA}$ & $14.9 \pm 4.6 \mathrm{aA}$ & $31.0 \pm 8.6 \mathrm{aA}$ & $39.6 \pm 9.4 \mathrm{aA}$ & $35.4 \pm 6.8 \mathrm{aA}$ & $28.5 \pm 6.0 \mathrm{aA}$ \\
\hline Parasitized by other species & $0 \pm 0$ & $0 \pm 0$ & $0 \pm 0$ & $9.3 \pm 4.1 \mathrm{a}$ & $24.7 \pm 6.0 \mathrm{a}$ & $15.3 \pm 4.4 \mathrm{a}$ \\
\hline \multicolumn{7}{|l|}{ WEEK 2} \\
\hline Total parasitized & na & na & na & $3.9 \pm 2.9 \mathrm{a}$ & $5.6 \pm 5.6 \mathrm{a}$ & $12.1 \pm 6.2 \mathrm{a}$ \\
\hline Alive \& parasitized & na & na & na & $3.9 \pm 2.9 \mathrm{a}$ & $5.6 \pm 5.6 \mathrm{a}$ & $0 \pm 0 \mathrm{a}$ \\
\hline Dead \& parasitized & na & na & na & $0 \pm 0 \mathrm{a}$ & $0 \pm 0 \mathrm{a}$ & $12.1 \pm 6.2 \mathrm{a}$ \\
\hline Dead & na & na & na & $20.7 \pm 6.2 \mathrm{a}$ & $45.6 \pm 8.5 \mathrm{a}$ & $30.0 \pm 6.6 \mathrm{a}$ \\
\hline Parasitized by other species & na & na & na & $1.7 \pm 1.3 \mathrm{a}$ & $14.1 \pm 6.0 \mathrm{ab}$ & $31.7 \pm 0.9 \mathrm{~b}$ \\
\hline
\end{tabular}

\footnotetext{
${ }^{1}$ Means within week, row and caged and uncaged classification followed by the same lowercase letter and means within treatment and row across caged and uncaged classification followed by the same uppercase letter are not significantly $(\mathrm{P}>0.05)$ different as determined by Tukey's Studentized range test (SAS, 2000). ${ }^{2}$ Not applicable, trial not conducted.
}

released per cage $(\bar{x}=69 \%$ alive and parasitized larvae per tree) versus the higher female release rate $(\bar{x}=24 \%$ alive and parasitized larvae per tree) (Table 2, Fig. 1).

The mean percentages of the collected hosts that were parasitized by $A$. polychrosidis (low release: $\bar{x}=6$ and high release $\bar{x}=14 \%$ ) and $M$. linearis (low release $\bar{x}=0$ and high release $\bar{x}=12 \%$ ) were relatively low in the caged trials (Table 3, Fig. 2). Death of host larvae due to parasitism was not discernable for these two braconids as parasitized larvae did not show evidence of their parasitized status as early instars. However, the percentage of dead hosts at the time of collection was not significantly larger $(\mathrm{P}>0.05)$ in the release treatments compared to the control for either parasitoid species.

\section{Uncaged trials}

All but the $M$. linearis releases in the uncaged trials resulted in movement of the parasitoids between treatment and control trees (Tables 2-3, Figs 1-2). Parasitism in the uncaged controls of these three parasitoid species indicates that individuals traveled at least $50 \mathrm{~m}$ postrelease to find hosts within the release orchard. Significantly more hosts were found to be alive and parasitized in the control $G$. variegata treatment in week one $\left(\mathrm{F}_{2,26}=\right.$ $5.1, \mathrm{P}=0.01)$. Although $A$. simplicipes moved onto control trees in the uncaged trials, released parasitoids still led to significantly higher overall parasitism in the high release treatments, for both weeks post-release (week one: $\mathrm{F}_{2,26}=9.8, \mathrm{P}=0.0007$; week two: $\mathrm{F}_{2,26}=8.1, \mathrm{P}<$ 0.002). Parasitism by $A$. polychrosidis, although low, was found to be significantly higher in the high release treat- 
TABLE 3. Mean percent of obliquebanded leafroller $( \pm \mathrm{SE})$ collected that were parasitized, dead or parasitized by other species one and two weeks post-release of 0 (control), 5 (low release) or 50 (high release) M. linearis or A. polychrosidis females onto caged and uncaged infested potted apple trees. ( $\mathrm{N}=9$ trees, 2 replications).

\begin{tabular}{|c|c|c|c|c|c|c|}
\hline \multirow{3}{*}{$\begin{array}{l}\text { Time collected and host } \\
\text { status post-release }\end{array}$} & \multicolumn{6}{|c|}{ Mean $\%$ of collected OBLR larvae per release treatment } \\
\hline & \multicolumn{3}{|c|}{ Caged treatment } & \multicolumn{3}{|c|}{ Uncaged treatments } \\
\hline & Control (0) & Low (5) & $\operatorname{High}(50)$ & Control (0) & Low (5) & High $(50)$ \\
\hline \multicolumn{7}{|c|}{ M. linearis (August - September releases) } \\
\hline \multicolumn{7}{|l|}{ WEEK 1} \\
\hline Parasitized & $0 \pm 0 \mathrm{a}^{1}$ & $0 \pm 0 \mathrm{a}$ & $12.0 \pm 7.6 \mathrm{a}$ & $0 \pm 0 \mathrm{a}$ & $0 \pm 0 \mathrm{a}$ & $2.1 \pm 1.5 \mathrm{a}$ \\
\hline Dead & $5.5 \pm 1.9 \mathrm{a}$ & $11.6 \pm 3.7 \mathrm{a}$ & $8.6 \pm 5.6 \mathrm{a}$ & $30.0 \pm 6.4 \mathrm{a}$ & $31.7 \pm 7.0 \mathrm{a}$ & $32.0 \pm 6.0 \mathrm{a}$ \\
\hline Parasitized by other species & $0 \pm 0$ & $0 \pm 0$ & $0 \pm 0$ & $3.1 \pm 2.0 \mathrm{a}$ & $0.4 \pm 0.4 \mathrm{a}$ & $2.5 \pm 1.7 \mathrm{a}$ \\
\hline \multicolumn{7}{|l|}{ WEEK 2} \\
\hline Parasitized & $\mathrm{na}^{2}$ & na & na & $0 \pm 0 \mathrm{a}$ & $0 \pm 0 \mathrm{a}$ & $0 \pm 0 \mathrm{a}$ \\
\hline Dead & na & na & na & $26.4 \pm 6.5 \mathrm{a}$ & $30.6 \pm 5.4 \mathrm{a}$ & $37.7 \pm 8.0 \mathrm{a}$ \\
\hline Parasitized by other species & na & na & na & $0 \pm 0 \mathrm{a}$ & $1.5 \pm 1.0 \mathrm{a}$ & $4.2 \pm 1.6 \mathrm{a}$ \\
\hline
\end{tabular}

A. polychrosidis (September - October releases)

WEEK 1

\begin{tabular}{lcccccc} 
Parasitized & $0 \pm 0 \mathrm{a}$ & $5.5 \pm 2.4 \mathrm{a}$ & $13.7 \pm 2.7 \mathrm{~b}$ & $0.2 \pm 0.2 \mathrm{a}$ & $1.1 \pm 0.8 \mathrm{a}$ & $3.8 \pm 1.4 \mathrm{a}$ \\
Dead & $4.4 \pm 2.0 \mathrm{a}$ & $11.1 \pm 4.6 \mathrm{a}$ & $6.0 \pm 3.0 \mathrm{a}$ & $21.6 \pm 6.6 \mathrm{a}$ & $16.7 \pm 4.1 \mathrm{a}$ & $9.1 \pm 5.5 \mathrm{a}$ \\
\begin{tabular}{rlc} 
Parasitized by other species \\
\multicolumn{1}{c}{ WEEK 2 }
\end{tabular} & $0 \pm 0$ & $0 \pm 0$ & $0 \pm 0$ & $11.9 \pm 4.4 \mathrm{a}$ & $13.2 \pm 3.4 \mathrm{a}$ & $7.4 \pm 3.3 \mathrm{a}$ \\
$\begin{array}{l}\text { Parasitized } \\
\text { Dead }\end{array}$ & na & na & na & $0 \pm 0 \mathrm{a}$ & $1.1 \pm 0.8 \mathrm{ab}$ & $3.3 \pm 1.1 \mathrm{~b}$ \\
Parasitized by other species & na & na & na & $29.3 \pm 3.8 \mathrm{~b}$ & $19.1 \pm 6.3 \mathrm{ab}$ & $7.8 \pm 3.1 \mathrm{a}$ \\
\hline
\end{tabular}

${ }^{1}$ Means within week, row and caged and uncaged classification followed by the same lowercase letter are not significantly $(\mathrm{P}>$ 0.05 ) different as determined by Tukey’s Studentized range test (SAS, 2000). ${ }^{2}$ Not applicable, trial not conducted.

ment versus the control in the caged treatment in week one $\left(\mathrm{F}_{2,26}=9.6, \mathrm{P}=0.0008\right)$ and in the uncaged treatment in week two $\left(\mathrm{F}_{2,26}=4.0, \mathrm{P}=0.03\right)$.

\section{Dead hosts}

When the cage effect was included in the analysis of each release trial, neither replication nor the presence or absence of a cage had a significant effect $(\mathrm{P}<0.05)$ on the number of dead, unparasitized leafroller host larvae found in any of the parasitoid release trials, although a high number of dead hosts were found on uncaged control and release trees in both weeks of the M. linearis trial (Table 3). This may have been due to the warmer summer temperatures as the cages did buffer temperature and humidity which may account for the lower number of dead larvae collected in caged treatments. In the first week of the trials, only caged $A$. simplicipes releases $\left(\mathrm{F}_{2,26}\right.$ $=8.3, \mathrm{P}=0.002$ ) and in the second week, uncaged $A$. polychrosidis releases $\left(\mathrm{F}_{2,26}=3.6, \mathrm{P}=0.04\right)$ had significant impacts on the percent of dead hosts with more dead hosts being found in the control trees. This indicates that some of the dead and parasitized hosts in the release treatments probably would have died even if not parasitized.

\section{Parasitism by other species}

Parasitism by wild species in the uncaged releases was highest in the spring $G$. variegata trials at 2 to $32 \%$ (Table 2, Fig. 1), lowest in the summer M. linearis trials at 0 to $4 \%$ (Table 3, Fig. 2) and ranged from 1 to $14 \%$ in the $A$. simplicipes and from 7 to $20 \%$ in the $A$. polychrosidis trials in the fall. In the fall release trials of $A$. simplicipes and A. polychrosidis, 70 and $74 \%$, respectively, of the wild parasitism was by an unidentified ichneumonid species, 18 and 14\%, respectively by unidentified eulophid ectoparasitoids, $21 \%$ by Apanteles species in the Apophua trials, and $0.1 \%$ by wild Apophua in the Apanteles trials. In the spring Glypta trials, only $3 \%$ of the wild parasitism was by unidentified eulophid ectoparasitoids, whereas $69 \%$ was by Apanteles species, $8 \%$ by an unidentified ichneumonid species, $15 \%$ by Apophua species and $5 \%$ by Meteorus species. Of the wild parasitism that did occur in the Macrocentrus uncaged releases, 51\% was by an unidentified eulophid, $22 \%$ by an unidentified ichneumonid species, $24 \%$ by Apanteles species and 2\% by Meteorus species.

\section{DISCUSSION}

In this study there were at least 5 to 36 hosts per tree available for parasitism, host feeding, consumption and/or intimidation. If the parasitoids were responding in a direct host density dependent fashion when released in the caged or uncaged trees, it would be within the theoretical capacity of 50 females of each parasitoid species released to parasitize all hosts. However, the percent parasitism in only the $A$. simplicipes trials came close to reaching the high levels expected, at least in the caged release trials. 


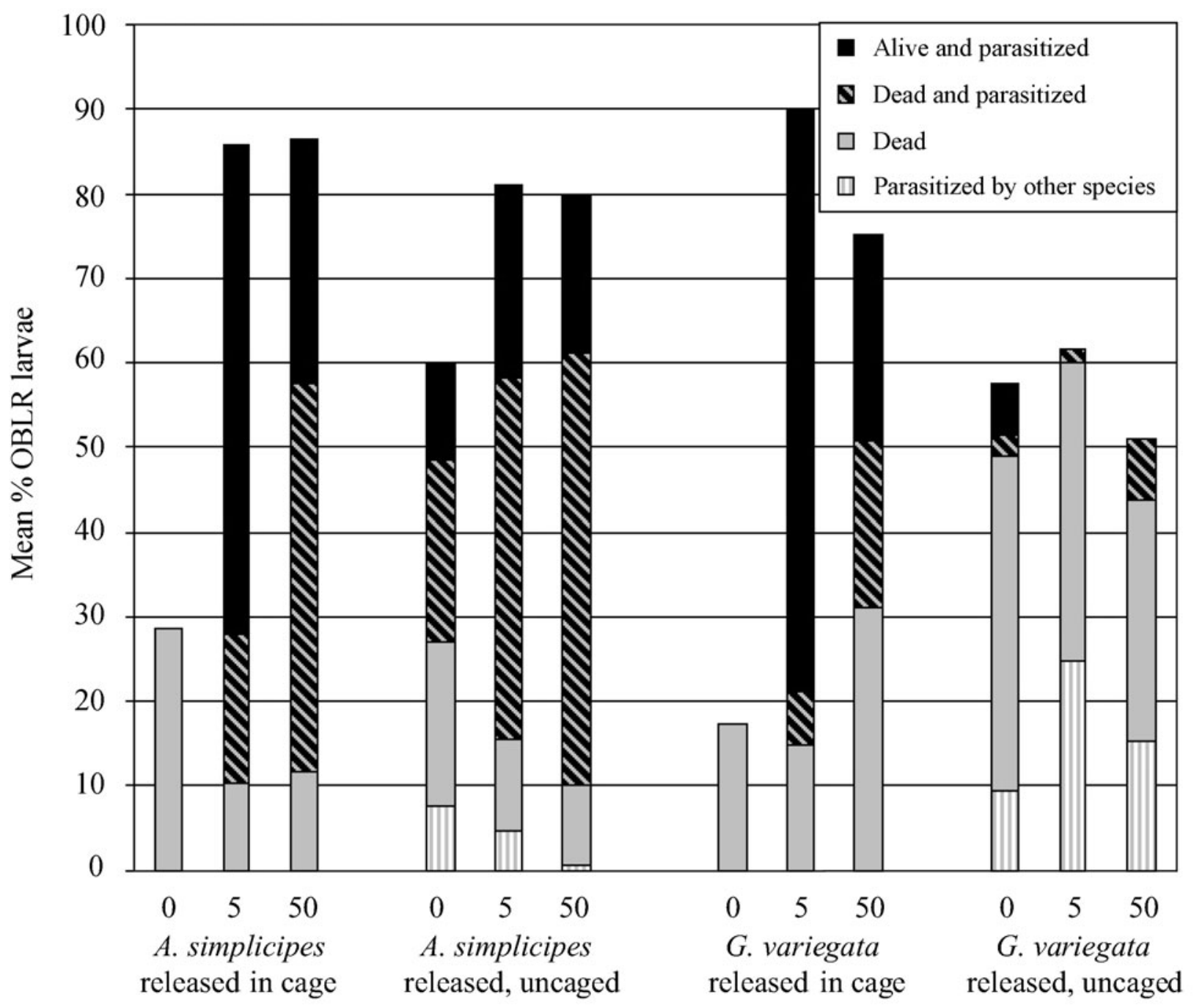

Fig. 1. Mean percent of total obliquebanded leafroller (OBLR) larvae found to be alive and parasitized, dead and parasitized, dead or parasitized by other species after collection from second instar OBLR-infested potted apple trees placed inside or outside screen cages, one week after release of 0, 5 or 50 female Apophua simplicipes or Glypta variegata. There was no temporal overlap of the two parasitoid trials. Nine trees per release rate; replicated twice over time.

Honey-water was provided and most females would be expected to survive for at least the first week of the study, assuming that they could find this food, as females of all four parasitoid species survived for means of at least 20 days in laboratory trials (Cossentine et al., 2004b, 2005, 2007). Conditions would be less amiable in the orchard environment and it is acknowledged that laboratoryreared parasitoids may have modified intrinsic foraging behaviour and may not respond as effectively to hosts on leaves as they do to hosts on artificial diet (Vet, 2001). Any of the four parasitoid species may not have been responding to kairomones resulting from obliquebanded leafroller larvae feeding on apple foliage and this aspect of the trials needs to be better understood. The fecundity of the two braconids as measured in laboratory trials (Cossentine et al., 2005) suggests that parasitism should have been higher in the field trials. It is possible that the time of year the trials were carried out may have been inappropriate for these two species, resulting in poor parasitism and the relatively warm temperatures under which the M. linearis were released would not be recommended for future trials. Similarly, the age and experience status of the released females require greater attention (Hougardy \& Mills, 2006). Although all four parasitoid species were old enough to begin parasitizing hosts based on laboratory data under summer conditions, the cooler or warmer conditions encountered in the field may have affected their fecundity (Foerster \& Butnariu, 2004; Castillo et al., 2006).

Although the total numbers of leafrollers per tree in this study were not counted prior to the parasitoid releases due to the instability of the early obliquebanded leafroller larvae after they are disturbed from feeding sites, the significantly lower numbers found in the $A$. simplicipes and $G$ variegata trials post-release implies that leafroller larvae are leaving the trees in response to parasitoid probing or are being consumed. Females of the two ichneumonid species cause leafroller mortality by hostfeeding and in a previous study, A. simplicipes have also been observed to chew early instar larvae, usually leaving 


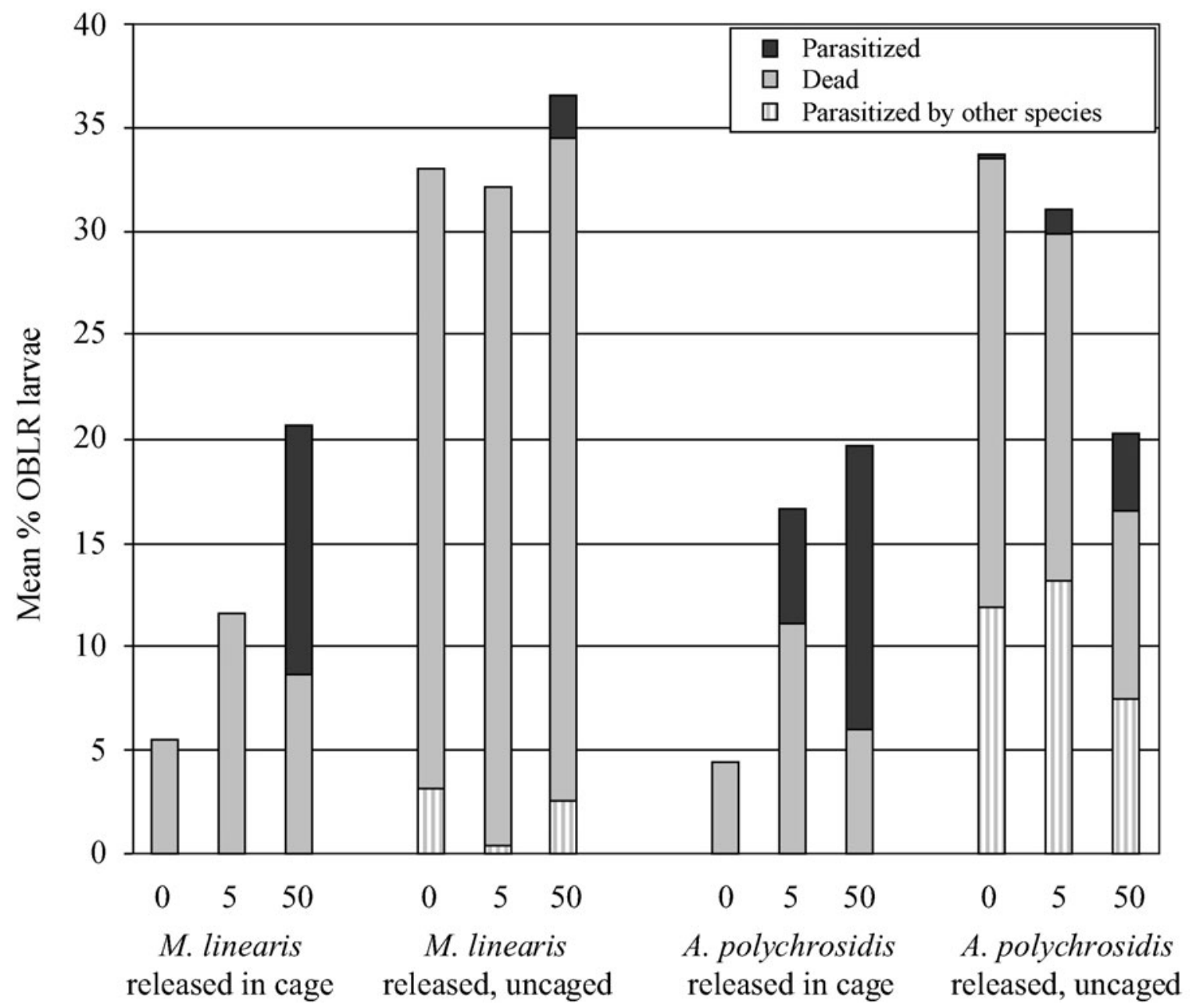

Fig. 2. Mean percent of total obliquebanded leafroller (OBLR) larvae found to be parasitized, dead or parasitized by other species after collection from second instar OBLR-infested potted apple trees placed inside or outside screen cages, one week after release of 0, 5 or 50 female Macrocentrus linearis or Apanteles polychrosidis. There was no temporal overlap of the two parasitoid trials. Nine trees per release rate; replicated twice over time.

the damaged remains (Cossentine et al., 2004b). Host-fed larvae in the $A$. simplicipes and $G$. variegata field trials may have died, however, most cadavers would be expected to remain associated with the leafroller webbing and consequently would be found under the dissecting microscope. In the laboratory, early instar leafrollers have frequently been observed exiting the silk webbing where they were feeding in response to ovipositor probing by both $A$. simplicipes and $G$. variegata. Neither of the two braconid species used in these release trials have been observed to host feed, consume or intimidate hosts and there was no significant impact of the release of either of these parasitoids on the total number of hosts found on the trees.

Host escape reactions to probing parasitoids have been recorded in other lepidopteran larvae in the field. Lightbrown apple moth, Eiphyas postvittana (Walker) (Lepidoptera: Tortricidae) larvae, exit webbing on leaves and spin down or crawl over the leaf surface when probed by the parasitoid Dolichogenidia tasmanica (Hymenoptera: Braconidae) (Suckling et al., 2001) and diamond-back moth, Plutella xylostella (Linnaeus) (Lepidoptera: Plutel- lidae) larvae, have been observed to hang by silk from plant leaves after attack by Diadegma spp. (Hymenoptera: Ichneumonidae) (Waage, 1983). Host escape behaviour in response to parasitoid probing in the orchard may cause a leafroller larva to move away from its feeding site, making it more vulnerable to movement off the tree and mortality from predation, starvation or desiccation. It is unfortunate that the number of leafrollers were not counted prior to the release of the parasitoids to confirm this hypothesis. Whether either of the ichneumonid parasitoid species used in this study do indeed have an intimidating impact on early host instars movement from feeding sites should be investigated as it may influence the overall impact of the indigenous species on host population densities.

Although the cages provided confinement and protection from wild predation and parasitism and thereby increased the potential for each released parasitoid species to maximize its impact on the sentinel hosts, the uncaged releases provided a more realistic assessment of each parasitoid potential efficacy. It is apparent from this study that it is important to consider the relative impact of 
release rates when considering a caged versus uncaged parasitoid release. The higher mortality of parasitized larvae at the higher female $A$. simplicipes and $G$. variegata release rate within cages may have been due to extreme superparasitism, predation, or to a limited extent, host feeding. The increased survival of ichneumonidparasitized host larvae under the lower pressure of five versus 50 released parasitoids was not seen in the uncaged releases supporting this hypothesis. By releasing the parasitoids in an unconfined area, these unrealistic results were avoided.

The uncaged releases also allowed wild parasitism which may support the accuracy of the timing of the release trials in that other host parasitoids were naturally present and actively searching for early instar hosts at the time of the release. The relatively low rate of natural parasitism that occurred in the M. linearis trials may indicate that the timing was sub-optimal for natural parasitism. The incidence of wild Apanteles parasitizing sentinel hosts in the $A$. simplicipes trials also indicates that the similarly timed $A$. polychrosidis releases were probably affected by unacknowledged wild Apanteles parasitism.

Results of controlled field releases need to be correctly interpreted in order to assess the potential for released parasitoids to parasitize or otherwise influence a target orchard pest. The results from this study indicate that releases of laboratory reared $A$. simplicipes may have a higher impact on obliquebanded hosts population densities than the other parasitoids tested; however, the differences in the levels of parasitism between the species indicate that many species specific variables such as responses to host-density and the importance, length and age-effect of learning host-related kairomones cues prior to release need to be better understood before this type of orchard trial can be used to compare the potential of individual parasitoid species to suppress host populations in orchard ecosystems.

ACKNOWLEDGEMENTS. The author is very grateful for the technical assistance of E. Deglow and L. Jensen, Agriculture and Agri-Food Canada, PARC, Summerland. This research was funded by the British Columbia Fruit Grower's Association, British Columbia Investment Agriculture Foundation and Agriculture and Agri-Food Canada.

\section{REFERENCES}

Bezemer T.M. \& Mills N.J. 2001: Host density responses of Mastrus ridibundus, a parasitoid of the codling moth, Cydia pomonella. Biol. Control 22: 169-175.

CARRIÈRE Y. 1992: Host plant exploitation within a population of a generalist herbivore, Choristoneura rosaceana. Entomol. Exp. Appl. 65: 1-10.

Castillo J., Jaca J.A., Pena J.E., Ulmer B.J. \& Hall D.G. 2006: Effect of temperature on the life history of Quadrastichus haitensis (Hymenoptera: Eulophidae), an endoparasitoid of Diaprepes abbreviatus (Coleoptera: Curculionidae). Biol. Control 36: 189-196.
Chapman P.J., Lienk S.E. \& Dean R.W. 1968: Bionomics of Choristoneura rosaceana. Ann. Entomol. Soc. Am. 61: 285-290.

Cossentine J., Jensen L., Deglow E., Bennett A., Goulet H., Huber J. \& O'Hara J. 2004a: The parasitoid complex affecting Choristoneura rosaceana and Pandemis limitata populations in organically managed apple orchards. Biocontrol Sci. Technol. 49: 359-372.

Cossentine J.E., Deglow E.K., Jensen L.B.M. \& Bennett A.M.R. 2004b: A biological assessment of Apophua simplicipes (Hymenoptera: Ichneumonidae) as a parasitoid of the obliquebanded leafroller, Choristoneura rosaceana (Lepidoptera: Tortricidae). Biocontrol Sci. Technol. 14: 691-699.

Cossentine J.E. Deglow E.K., Jensen L.B.M. \& Goulet H. 2005: Biological assessment of Macrocentrus linearis Nees and Apanteles polychrosidis Viereck (Hymenoptera: Braconidae) as parasitoids of the obliquebanded leafroller, Choristoneura roscaceana (Lepidoptera: Tortricidae). Biocontrol Sci. Technol. 15: 711-720.

Cossentine J.E., Deglow E.K., Jensen L.B.M. \& Bennett A.M.R. 2007: A biological assessment of Glypta variegata (Hymenoptera: Ichneumonidae) as a parasitoid of Choristoneura rosaceana (Lepidoptera: Tortricidae). Biocontrol Sci. Technol. 17: 325-329.

DYcK V.A. \& GARDINER M.G.T. 1992: Sterile-insect release programme to control the codling moth Cydia pomonella (L.) (Lepidoptera: Olethreutidae) in British Columbia, Canada. Acta Phytopathol. Entomol. Hungar. 27: 219-228.

Foerster L.A. \& Butnariu A.R. 2004: Development, reproduction and longevity of Telenomus cyamophylaxi egg parasitoid of the velvetbean caterpillar Anticarsia gemmatalis, in relation to temperatures. Biol. Control 29: 1-4.

Hougardy E. \& Mills N.J. 2006: The influence of host deprivation and egg expenditure on the rate of dispersal of a parasitoid following field release. Biol. Control 37: 206-213.

LeWIS W.J. \& Martin JR. W.R. 1990: Semiochemicals for use with parasitoids: Status and future. J. Chem. Ecol. 16: 3067-3089.

Madsen H.F. \& Procter P.J. 1982: Insects and Mites of Tree Fruits in British Columbia. Ministry of Agriculture and Food, Victoria, BC, $70 \mathrm{pp}$.

Noldus L.P.J.J. 1989: Semiochemicals, foraging behaviour and quality of entomophagous insects for biological control. $J$. Appl. Entomol. 108: 425-451.

SAS 2000: SAS Version 8.1. SAS Institute, Cary, NC.

Shorey H.H. \& Hale R.L. 1965: Mass-rearing of the larvae of nine noctuid species on a simple artificial medium. J. Econ. Entomol. 58: 522-524.

Suckling D.M., Burnip G.M., Gibb A.R., Daly J.M. \& ARMSTRONG K.F. 2001: Plant and host effects on the leafroller parasitoid Dolichogenidia tasmanica. Entomol. Exp. Appl. 100: $253-260$.

Van Driesche R.G. \& Bellows T.S. JR. 1996: Biological Control. Chapman \& Hall, New York, 539 pp.

VAn Lenteren J.C. \& Woets J. 1988: Biological and integrated control in greenhouses. Annu. Rev. Entomol. 33: 239-269.

Vet L.E. 2001: Parasitoid searching efficiency links behaviour to population processes. Appl. Entomol. Zool. 36: 399-408.

WAAGE J.K. 1983: Aggregation in field parasitoid populations: foraging time allocation by a population of Diadegma (Hymenoptera: Ichneumonidae). Ecol. Entomol. 8: 447-453.

Received July 14, revised and accepted January 3, 2008 